\title{
Mobilidades humanas e interações sociais entre comunidades rurais na fronteira Brasil-Bolívia ${ }^{1}$
}

\author{
Human mobilities and social interactions between rural \\ communities on the Brazil-Bolivia border
}

\section{Movilidades humanas y las interacciones sociales entre comunidades rurales en la frontera Brasil-Bolivia}

\author{
Edgar Aparecido Costa \\ edgarac10@gmail.com \\ Universidade Federal de Mato Grosso do Sul \\ Vania Oliveira Sabatel \\ vsabatel@bol.com.br \\ Agência de Desenvolvimento Agrário e Extensão Rural
}

\begin{abstract}
Resumo: O objetivo deste trabalho é analisar as mobilidades humanas e as interações sociais entre grupos populacionais dos assentamentos rurais brasileiros e a comunidade rural boliviana El Carmen de la Frontera, localizados na fronteira Brasil-Bolívia. A pesquisa se apoiou na técnica da observação e descrição somadas aos trabalhos de campo. Foram realizadas 22 entrevistas em El Carmen de la Frontera, 50 nos assentamentos rurais brasileiros, 5 com gestores da AGRAER e 3 com gestores do INCRA, que foram gravadas com o consentimento das pessoas. Existe intensa mobilidade humana para um e outro lado da fronteira, além de forte interação social entre as populações rurais no nível individual e das coletividades.
\end{abstract}

Palavras-chave: Fronteira. Território. Corumbá, MS.

Abstract: This study analyzes human mobility and social interactions among population groups in Brazilian rural settlements and the rural Bolivian community of El Carmen de la Frontera, which is located on the Brazil-Bolivia border. The research was based on observation and description, together with field work. Twenty-two interviews were conducted in El Carmen de la Frontera and 50 in Brazilian rural settlements, with 5 managers of AGRAER and 3 of INCRA. The interviews were recorded with the consent of those being interviewed. It was observed that there is intense human mobility towards and across the border, and a strong social interaction among rural populations, both individually and collectively.

Keywords: Border. Territory. Corumbá, MS.

Resumen: El objetivo de este trabajo es analizar la movilidad humana y las interacciones sociales entre los grupos de población de los asentamientos rurales de Brasil y de

1 Este artigo é parte da dissertação de Mestrado em Estudos Fronteiriços, na Universidade Federal de Mato Grosso do Sul, modificada na sua composição escrita - mantidos os dados primários. 
la comunidad boliviana rural de El Carmen de la Frontera, situados en la frontera entre Brasil y Bolivia. La investigación se apoyó en la técnica de la observación y la descripción, junto con el trabajo de terreno. Se realizaron 22 encuestas en El Carmen de la Frontera, 50 en los asentamientos rurales de Brasil, con 5 gerentes de la AGRAER y 3 del INCRA, que fueron grabadas con el consentimiento de las personas. Se observó que existe ya una intensa movilidad humana través de la frontera, de un lado y otro de la frontera, y una fuerte interacción social entre las poblaciones rurales a nivel individual y de las colectividades.

Palabras clave: Frontera. Territorio. Corumbá, MS.

\section{INTRODUÇÃO}

A fronteira é uma área de importância geográfica estratégica, pois nela coexistem diversos tipos de relações de troca, de articulação e de comunicação entre, pelo menos, dois territórios nacionais, que se revelam como desafios e oportunidades para as políticas públicas bilaterais.

O estudo foi realizado na fronteira Brasil-Bolívia, na área próxima à linha limítrofe, entre o município de Corumbá (Mato Grosso doSul, Brasil) e a Segunda Sección Municipal de Puerto Quijarro (província de Germán Busch, departamento de Santa Cruz, Bolívia), onde há décadas estão instalados pequenos agricultores.

No lado do território boliviano está situada a comunidade rural de El Carmen de la Frontera, ou Carmo, como é conhecida pelos brasileiros, composta por cerca de 30 famílias aglomeradas, na sua maioria com laços de parentesco. No lado brasileiro encontram-se os assentamentos rurais Tamarineiro I, Tamarineiro II, Paiolzinho e Taquaral, com mais de 500 famílias que se configuram num habitat disperso.

O presente trabalho está focado num espaço geográfico onde afloram maiores possibilidades de relacionamento pela proximidade geográfica imediata, a ponto de se confundir onde fica um e outro território nacional. Apenas a estrada de chão, que vai de Corumbá ao Jacadigo (Estrada Jacadigo), separa fisionomicamente os assentamentos Tamarineiro I e Tamarineiro II Sul da comunidade boliviana El Carmen de la Frontera (Figura 1). Na paisagem, as comunidades se confundem, tendo apenas o marco de concreto e as bandeiras bolivianas hasteadas em algumas casas como indicativo simbólico de demarcação dos territórios.

Tendo em vista este contexto, o objetivo do presente trabalho é analisar as mobilidades humanas e as interações sociais entre as populações vizinhas do limite internacional dos assentamentos rurais brasileiros Paiolzinho, Tamarineiro I e Tamarineiro II e a comunidade rural boliviana El Carmen de la Frontera. O pano de fundo dessa investigação foi a perspectiva de pensar o desenvolvimento territorial para áreas rurais fronteiriças.

Foi utilizada a técnica da observação, ancorada por trabalho de campo, tendo por apoio questionários, roteiros de entrevistas e também a descrição da paisagem. Foram realizadas 22 entrevistas em El Carmen de la Frontera, 50 nos assentamentos rurais brasileiros, 5 com gestores da AGRAER e 3 com gestores do INCRA, que foram gravadas com 
o consentimento das pessoas. O trabalho de campo ocorreu durante o ano de 2012, com duração média de 30 minutos a uma hora para cada entrevista.

Figura 1 - Vista geral de El Carmen de la Frontera.

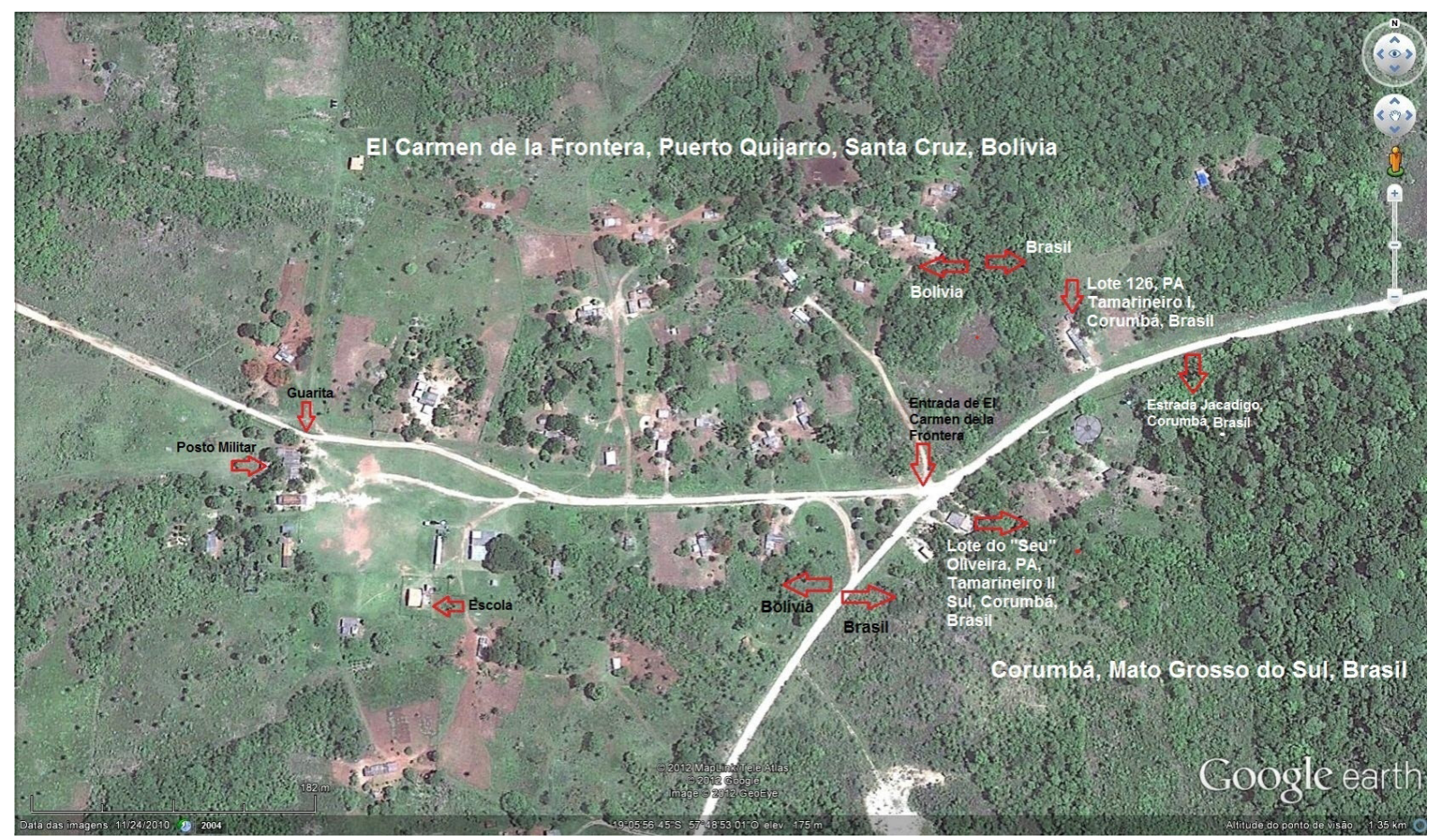

Fonte: GOOGLE EARTH (2012)

Org: COSTA (2012).

No caso boliviano, o primeiro contato foi feito com uma liderança local - a professora da comunidade, que era a representante local na época. A primeira conversa foi na escola, no final da aula. $O$ fato de ela ser professora facilitou o entendimento da proposta deste trabalho, já que compreendia o processo de pesquisa, tendo inclusive manifestado o desejo de cursar mestrado em Educação, na Bolívia. Essa contribuição ajudou a ampliar os contatos, a facilitar a "entrada" no universo dos sujeitos a serem entrevistados e a conquistar a credibilidade dos moradores locais. Mesmo assim, as perguntas incomodaram alguns deles pelo fato de ser a primeira vez que se realizava uma pesquisa no local e a maioria desconhecia os procedimentos (questionários e entrevistas) e se sentiram "investigados". Dessa forma foi preciso, em cada visita, apresentar a carteira de estudante e explicar qual o objetivo da pesquisa. As palavras "estudante" e "universidade" são muito bem aceitas no local.

Do lado brasileiro, a experiência profissional favoreceu o contato, pois já se trabalhava com os camponeses e se conhecia grande parte dos entrevistados. As entrevistas com as lideranças foram marcadas por telefone, ocorrendo na casa ou no trabalho do entrevistado, ou na residência do pesquisador.

$\mathrm{O}$ artigo foi estruturado de modo a discutir os conceitos estruturantes para se pensar o desenvolvimento territorial em áreas fronteiriças e descrever as mobilidades territoriais e as interações sociais fronteiriças, partindo, primeiramente, da caracterização de cada um dos agrupamentos populacionais que compõem a franja fronteiriça estudada. 


\section{TERRITÓRIOS, FRONTEIRA E DESENVOLVIMENTO}

O processo de globalização ampliou as competições em diferentes setores econômicos para atender aos padrões exigidos pelo modo capitalista de produção. Nesse sentido, as fronteiras passaram a ser consideradas zonas estratégicas pela proximidade, pelo contato geográfico. Contudo, o fato de estar perto do outro não é prerrogativa das interações sociais entre os grupos populacionais vizinhos e, por isso, a necessidade de se estudar cada caso isoladamente. Costa (2011) argumenta que em qualquer situação, condição ou localização, os relacionamentos entre os fronteiriços são historicamente construídos, mediados pela política e ideologia dos governos centrais, mas, sobretudo pelas necessidades de trocas entre os habitantes dessas localidades.

Quando se menciona a possibilidade de desenvolvimento para a população de alguma área situada na franja do limite internacional, não é possível trabalhar apenas com os eventos que ocorrem dentro dos limites territoriais. É igualmente importante compreender as territorialidades que se desenvolvem nas vizinhanças e, fundamentalmente, as que atravessam e que tensionam o território propositivo. Daí a importância de se compreender o conceito de território sob a perspectiva do desenvolvimento e as especificidades dos territórios de fronteira.

O território é entendido, nesta reflexão, como um espaço delimitado por e a partir de relações de poder (SOUZA, 1995), cujas materialidades são reflexos das imaterialidades e das ações territoriais dos agentes e atores do espaço (SAQUET, 2007). Costa (2009) acrescenta que o território pressupõe um espaço físico dotado de recursos naturais e materiais delimitados política e/ou culturalmente. Esses agentes podem não ser exclusivos de um território e tampouco são relegados a desenvolverem territorialidades restritivas ao mesmo. É possível que alguns atores e agentes da produção territorial sejam autóctones, mas isso não é uma regra no mundo atual, já que são cada vez mais impelidos/compelidos a participar com mais frequência das etapas produtivas do capitalismo global. Os territórios fronteiriços são, ainda, mais complexos.

As fronteiras são formadas por franjas territoriais de países diferentes, articuladas numa contiguidade territorial, controlada e confrontada por diferentes forças e relações de poder (COSTA, 2013). Evoca um espaço geográfico que contém mais de um território nacional. "A fronteira é uma construção sociopolítica que contém o limite internacional" (COSTA, 2013, p. 67). Diferentemente dos territórios, a fronteira é uma área geográfica com limites imprecisos, é variável e dinâmica, que ora retrai, ora expande, conforme os jogos territoriais de poder (COSTA, 2011). Essa condição, aliada ao fato de a fronteira abranger diferentes jurisdições, dificulta as ações de cooperação interinstitucional.

Em cada uma das bandas fronteiriças, o território é sentido e respeitado, cujas motivações se devem às diferentes ações que lhe são impressas, ao jogo de forças, aos fluxos e às normas que o atravessam. São modelados e desenhados pelos distintos atores que atuam sobre ele, tal como um campo de forças, cuja regulamentação ocorre pelo arranjo de poder entre seus componentes. 
O encontro/confronto de territórios na fronteira não inibe os fluxos para um e outro lado. A mobilidade humana acena para escolhas territoriais que tragam algum tipo de benefício ao indivíduo e/ou ao seu grupo. Benedetti $(2011$, p. 36) define mobilidade como "un tipo particular de relación social ligada al cambio de localización de las personas y/o de los bienes; es una estrategia de reproducción social a partir de la relación entre lugares, definiendo trayectorias espaciotemporales complejas".

Costa (2013, p. 68) acrescenta que cada passagem de fronteira "tem características particulares arranjadas em razão das combinações territoriais possíveis a cada tempo, a cada indivíduo/coletividade".

A partir deste entendimento, vislumbram-se enormes desafios para os governos adotarem medidas eficazes de desenvolvimento dos territórios em zonas de fronteira, em razão da contradição aparente das próprias racionalidades territoriais. As políticas públicas são aplicadas apenas dentro dos limites da jurisdição, enquanto nas fronteiras as mobilidades humanas frequentemente avançam para além dos limites, produzindo territorialidades que afetam a lógica local.

Contudo, a fronteira não é necessariamente um problema. Na verdade é, muitas vezes, tratada como problema por aqueles que não entendem ou não desejam entender suas dinâmicas. Frequentemente suas potencialidades são apropriadas por agentes e atores espaciais que operam em ambas as bandas territoriais, levando em consideração as vantagens econômicas produzidas pelas diferenças cambiais, dentre outras. As fronteiras são, pois, portadoras de oportunidades. Segundo Benedetti (2011), no espaço fronteiriço, devido às várias territorialidades que se cruzam e as assimetrias estruturais e conjunturais, o outro lado pode se transformar num lugar estratégico para o intercâmbio, obtenção/aplicação de recursos e fonte de riquezas.

A fronteira não é vista como limite por seus moradores. Pelo contrário, ela influencia o contato e a aproximação, abrindo oportunidades e possibilidades que contribuem para o dinamismo do território, ao mesmo tempo em que são (re)construídas pelas tensões internas e pressões externas ao território. Para House (1980), dependendo do grau de abertura e da diversidade dos elementos existentes, são gerados fluxos e relações entre fronteiriços, motivados pela busca de complementariedade em setores como saúde, educação, comércio e outros serviços. Ao mesmo tempo, cria-se um ambiente de disputas constantes entre os territórios, que acaba estimulando o fortalecimento de nacionalismos, conforme acontece na fronteira estudada.

Nogueira (2007) entende que a convivência com a diferença instiga o fortalecimento de símbolos próprios de cada nação, sua história e cultura, além do sentimento de pertencimento. Isso torna a fronteira um lugar de referência identitária. Contudo, ao mesmo tempo em que existe a necessidade de preservar o território, contraditoriamente se impõe a vontade de avançar para além dos limites territoriais e estabelecer relações com o outro. Nesse sentido, a fronteira é tanto um espaço de tensão quanto de integração. Por isso Oliveira (2005) escreve que as diferentes relações de trocas realizadas nas zonas de fronteira se revelam em desafios e oportunidades para as políticas públicas bilaterais. 
Por serem uma localidade estratégica de defesa/controle do território nacional, as fronteiras são motivos da indução do assentamento humano pelos governos centrais. Esse pensamento é compartilhado com Girardi (2009), para quem alguns assentamentos, no Brasil, foram criados em regiões de fronteira como estratégia governamental para amenizar conflitos sociais e dar continuidade à reforma agrária conservadora, preservando a elite agrária.

Soares (1972) já dizia que a "vivificação" das fronteiras, ou seja, o povoamento das áreas fronteiriças, é e deve ser estimulada pelo Estado para manter a proteção e segurança dos limites nacionais. Para ele, a fronteira é o resultado da política e deve ser viva, protegida e vigilante para enaltecer a organização de um povo e fortalecer a nacionalidade.

Outro argumento é o preço do uso do solo. Michelotti et al (2007) destacam que os preços das terras de fronteira são menores devido à fraca presença de infraestrutura e de serviços básicos (características, também, das frentes pioneiras), resultando na instalação precária e baixa qualidade de vida das famílias assentadas.

As fronteiras são, em geral, locais onde as escalas territoriais se confundem. Existe uma passagem brusca do local para o internacional. Além disso, e também por isso, confluem para essas áreas interesses e ações diversas que tornam os espaços de fronteira com marcante complexidade, dificultando a proposição de um desenvolvimento territorial sustentável.

Saquet (2007) aponta que é necessário conhecer essas especificidades para se construir, junto com os legítimos interessados, de forma participativa, os alicerces do desenvolvimento territorial. Devem-se considerar as temporalidades e as territorialidades presentes, bem como os sonhos e os distintos interesses.

Como os espaços fronteiriços encerram em si os limites jurisdicionais - e isso implica a possibilidade de indução de políticas públicas em apenas uma das bandas territoriais -, a operacionalização do desenvolvimento territorial só poderá ocorrer através da ação participativa dos atores sociais dos territórios envolvidos. Nessa perspectiva, o diálogo é de fundamental importância, pois, segundo Britts e Costa (2009), fortalece as relações de igualdade no território, gerando um processo permanente de relacionamento e comprometimento entre as partes para a concretização de um objetivo comum. Caberá a cada grupo tensionar os governos de seu território para implementar as ações/medidas acordadas pelo diálogo entre os moradores de uma e outra franja fronteiriça.

Para tanto, é necessário o conhecimento das totalidades que formam os territórios que se encontram na fronteira estudada, pois o desenvolvimento territorial remete pensar no conjunto de atividades econômicas que estão contidas no território, assim como analisar as funções políticas e ambientais construídas e a serem construídas. Essa condição é dada pelas características do território que, para Guanzirolli (2006), é multissetorial e multifuncional, mutável e provisório, cuja construção depende da relação de proximidade entre os diferentes atores sociais com diferentes interesses, necessitando de um espaço de negociação e conciliação para definir as prioridades de um lugar.

É preciso, pois, compreender cada comunidade e suas interações sociais. A fronteira é, portanto, uma porta que abre oportunidades de desenvolvimento para os dois lados 
e também para a construção de uma forma de atuação autônoma dos seus moradores e no reconhecimento de um "terceiro lado": o território rural fronteiriço.

\section{O ASSENTAMENTO TAMARINEIRO I}

O assentamento Tamarineiro I acompanha a linha de limite internacional e foi instituído através pela Resolução n ${ }^{\circ} 142$, de 03 de Julho de 1984, do INCRA, que destinava área de 3.797,1623 ha, doadas pelo Grupo Chamma (Portaria n 061 de 19 de março de 1984), resultando em 126 unidades agrícolas familiares e um núcleo urbano com áreas irregulares variando entre 14 e 30 ha.

O assentamento Tamarineiro I, como ficou conhecido, herdou o nome da de uma antiga fazenda. O algarismo I foi acrescentado por se tratar do primeiro dos assentamentos com o mesmo nome. Foi também o primeiro assentamento rural criado no estado do Mato Grosso do Sul e, conforme lembra um dos entrevistados², funcionário do INCRA, a sua criação foi notícia nacional: "Me lembro do dia em que as famílias de agricultores chegaram a Corumbá, até a TV Globo estava aqui, houve carreata pela rua Frei Mariano".

Não houve um processo seletivo das famílias. Grande parte das pessoas que ocuparam o assentamento Tamarineiro I trabalhavam ou moravam na antiga fazenda que fora doada. Outra parte foi composta por famílias trazidas pelo INCRA de uma área de tensão e conflitos sociais, nas proximidades de Naviraí, MS, que já participavam da luta pela terra, principalmente nas fazendas Três Rios e Jequitibá. As famílias restantes eram de Corumbá.

Na ocupação dessa área rural não houve conflitos e nem lutas pela terra. As famílias vindas de Naviraí acamparam, por pouco tempo, às margens da estrada Jacadigo, conhecida como "estrada branca", próximo ao antigo prédio da Receita Federal, conhecido como "o redondo" e aguardaram apenas o INCRA "cortar" as terras em parcelas. A dificuldade maior foi de adaptação a um meio físico difícil, conforme pode ser observado nas palavras de um morador pioneiro do Tamarineiro I’:

Nós chegamos aqui em 83, éramos mais ou menos 40 famílias e viemos de ônibus e nossa mudança num caminhão. O Exército fez o acampamento com as lonas pretas a uns 500 metros do Carmo, e era muito sofrimento... foi uma batalha difícil. A água pra beber era levada para as famílias em caixas de mil litros, não tinha nada pra comer e os banhos eram no córgo [córrego] e na época não tinha estradas, a não ser a "estrada branca", as máquinas abriram só os "picadão" e nós, os parceleiros, que fomos abrindo as "picadas" até os lotes.

A paisagem havia sido transformada quando as famílias ocuparam os lotes. A área já tinha sido desmatada, transformando-se num capoeirão e muita madeira já fora sido retirada para atender as demandas dos fornos de carvão da antiga fazenda pertencente

2 Entrevista realizada no dia 14 de outubro de 2011.

3 Entrevista realizada no dia 15 de agosto de 2011. 
ao Grupo Chamma. A principal atividade do grupo era a siderurgia e muitos dos antigos trabalhadores que permaneceram na área deram continuidade a essa atividade, como fonte geradora de renda, numa forma de reterritorialização.

Após o parcelamento dos lotes foi realizado o sorteio para a ocupação definitiva, com direito a contestação e trocas, já que o assentamento possuía muitas áreas com afloramentos rochosos. Alguns produtores iniciaram, com muita dificuldade, pequenas produções agrícolas para a subsistência, como roças de mandioca e milho. Dados da EMPAER (1988/1989, atualmente AGRAER) indicam que as famílias de Corumbá não tinham tradição agrícola; já as famílias oriundas do município de Naviraí tinham conhecimentos de agricultura, diversificaram e introduziram novas culturas no município. Até hoje, muitas delas ainda mantêm a agricultura como atividade de subsistência, o que demonstra o vínculo com a terra e com suas tradições.

Os lotes possuem luz elétrica, com um transformador para cada cinco lotes. A conta de energia é dividida entre todos os parceleiros (donos de parcelas de terra). Porém, muitos deixam ou não conseguem pagar, prejudicando a gestão e o abastecimento da água feito a partir de três poços artesianos, distribuída por rede encanada para os lotes do assentamento. Alguns lotes também possuem cisterna para a captação da água da chuva e outros têm mina d'água. Dados da Secretaria Municipal de Saúde de Corumbá indicam que o abastecimento de água no assentamento é, na maioria (75\%), feito pela rede pública, quase $8 \%$ provêm de poço ou nascente e os demais por outras formas.

As principais atividades agropecuárias desenvolvidas são: a pecuária bovina de leite e de corte, a criação de pequenos animais, a horticultura e, em alguns lotes, a agricultura de subsistência, com venda de excedentes. Segundo Cardoso (2002), os solos são férteis, porém, o cultivo agrícola é limitado devido, principalmente, à deficiência hídrica. Tais limitações são reconhecidas pelos agricultores e comprometem o desenvolvimento das suas lavouras e inserção no mercado local, já que não é garantida a produção contínua e em escala comercial. As palavras de um morador do Tamarineiro $\mathrm{I}^{4}$ demonstram essas dificuldades, bem como deixam transparecer o conflito cultural entre os assentados e a competição por mercado com os bolivianos:

Quando chegamos aqui, a turma que veio de fora falava que os "bolivianos" eram preguiçosos, não aproveitavam a terra que tinham. Mas hoje em dia, nós ficamos quase igual a eles, porque vemos a dificuldade que enfrentamos. Lá de onde viemos expandia o serviço. Aqui, apesar de também não precisar de adubo, tem a dificuldade da pedra, da água e você planta e a mercadoria acaba ficando na terra. Já chegamos a colher muito feijão, mas aqui eles não querem, porque somos do assentamento. Os produtores de outras regiões ou da Bolívia vêm com o caminhão cheio e os compradores dizem que com eles o tempo que precisarem tem a mercadoria e nós é apenas um tempo que tem, outro não.

O núcleo ou centro comunitário, com área de 3,9848 ha, está localizado próximo da estrada Jacadigo e é destinado ao uso coletivo. Sua infraestrutura é composta pela sede

4 Entrevista realizada no dia 15 de agosto de 2011. 
da associação, um barracão em estado precário para guarda dos maquinários, um posto de saúde e um prédio onde está instalada a Escola Municipal Eutrópia Gomes Pedroso (que conta com quadra de esportes - o único espaço de lazer existente no assentamento), administrada pela Prefeitura Municipal de Corumbá.

O posto de saúde atende todos os assentamentos dessa região de fronteira, porém, de forma insuficiente. $O$ atendimento médico é somente clínica geral, uma vez por semana, e os atendimentos odontológicos duas vezes por semana.

Atualmente o assentamento Tamarineiro I é considerado emancipado pelo INCRA e muitos parceleiros fundadores já faleceram. Existem ainda os que foram remanejados para outros lotes, os que abandonaram ou venderam as terras e os que não possuem documentos. Também existem lotes cujos proprietários residem na zona urbana e possuem funcionários que "cuidam" da terra. Segundo Sabatel, Zarate e Costa (2011), existem proprietários que compraram mais de um lote no local, configurando novas territorialidades e desfigurando a estrutura fundiária local.

Alguns lotes do assentamento fazem divisa com a Bolívia e existem estradas de livre acesso para o outro país, conhecidas como "cabriteiras". Esse nome se deve às péssimas condições apresentadas por elas no começo da ocupação dos assentamentos. A passagem para a Bolívia era repleta de pedras e buracos, sendo de difícil acesso que, na fala dos assentados: "só cabrito consegue passar". Essa dificuldade não é mais a mesma, porém, o nome permaneceu.

O assentamento conta com 427 moradores, sendo que $57,61 \%$ são homens e $42,39 \%$ mulheres (Tabela 1). A maioria da população se encontra na faixa etária de 20 a 39 anos, caracterizando uma população em idade ativa. Portanto, as famílias apresentam força de trabalho disponível e potencial reprodutivo, com expectativa de aumentar a população. A média de membros por família é de 3 a 4 pessoas.

Tabela 1 - População do assentamento Tamarineiro I, segundo classes de idade, Corumbá-MS, 2012

\begin{tabular}{|c|c|c|c|c|c|c|c|c|c|c|c|}
\hline \multirow[b]{2}{*}{ Sexo } & \multicolumn{11}{|c|}{ Faixa etária (anos) } \\
\hline & $<1$ & 1 a 4 & 5 a 6 & 7 a 9 & $\begin{array}{c}10 \mathrm{a} \\
14\end{array}$ & $\begin{array}{c}15 \mathrm{a} \\
19\end{array}$ & 20 a 39 & $\begin{array}{c}40 \mathrm{a} \\
49\end{array}$ & $\begin{array}{c}50 \mathrm{a} \\
59\end{array}$ & $>60$ & Total \\
\hline Masculino & 0 & 5 & 7 & 14 & 36 & 32 & 62 & 24 & 20 & 46 & 246 \\
\hline Feminino & 0 & 10 & 8 & 9 & 22 & 21 & 44 & 21 & 18 & 28 & 181 \\
\hline Número de Pessoas & 0 & 15 & 15 & 23 & 58 & 53 & 106 & 45 & 38 & 74 & 427 \\
\hline
\end{tabular}

Fonte: SAS/DAB-DATASUS; SMS; SIAB, 2012.

\section{ASSENTAMENTOS TAMARINEIRO II E PAIOLZINHO}

O assentamento Tamarineiro II surgiu onze anos depois do Tamarineiro I, através da aquisição por arrecadação sumária pelo INCRA da outra parte da fazenda de propriedade do Grupo Chamma, com área de 10.635,5828 ha. A Portaria n 117, de 15 de dezembro de 1995, criou o assentamento Tamarineiro II, que previa a construção de 400 unidades agrícolas familiares e implantação de infraestrutura. No DOU nº 116, de 20/06/1997, 
foi feita uma retificação da Superintendência Regional do INCRA, aumentando para 428 unidades.

Já as terras do assentamento Paiolzinho foram adquiridas pelo INCRA (também do Grupo Chamma) por desapropriação de outra parte da fazenda Tamarineiro, com área de 1.196,7523 ha. O assentamento foi criado pela Portaria $n^{\circ}$ 9, de 11 de março de 1996, prevendo a construção de 50 unidades agrícolas familiares, passando a 72 unidades pela retificação da Superintendência Regional do INCRA/MS n 116 , de 20 de junho de 1977.

O nome Paiolzinho se deve a um pequeno paiol existente na antiga fazenda do Grupo Chamma. A denominação de Tamarineiro foi herdada da antiga fazenda, e o algarismo II provém do fato de ser o segundo assentamento com o mesmo nome na região. Como o assentamento Paiolzinho está localizado dentro do perímetro do assentamento Tamarineiro II, provocou seu desmembramento em Tamarineiro II Norte e Tamarineiro II Sul.

A maioria das famílias que ocuparam os assentamentos Tamarineiro II e Paiolzinho vieram mediante a luta pela terra, que foram intensas no início da década de 1990. Foram trazidas por movimentos sociais, como a Fetagri e o MST, de outras áreas do estado de Mato Grosso do Sul. Ficaram três anos acampados na estrada Jacadigo e houve muitos conflitos com os posseiros que ali estavam. Segundo a então presidente do Sindicato dos Pequenos Trabalhadores Rurais ${ }^{5}$, era uma batalha constante num meio físico difícil, sendo que muitas vezes os acampados foram despejados da terra por liminares judiciais na disputa com os posseiros: “Nós fomos despejados seis vezes, mas íamos e voltávamos para a terra. Era muito difícil, passamos muita necessidade e nessas idas e vindas pessoas adoeciam e perdemos algumas crianças nessa luta".

Após os conflitos mais árduos, em que animais e casas dos posseiros foram incendiados pelos acampados, o governo indenizou os posseiros para que deixassem a terra e o INCRA demarcou as parcelas, sorteou os lotes e assentou os acampados.

O assentamento Tamarineiro II Norte possui área total de 1.247,2775 ha, com 76 lotes variando entre 14 e 30 há, e reserva legal coletiva de 119,6200 ha. Conta com espaço comunitário de 3,9848 ha, sendo aproveitada somente a metade dessa área. As únicas benfeitorias existentes são um prédio em estado precário de conservação e um resfriador de leite. Não possui nenhum espaço de lazer comunitário.

A sua população é de 357 pessoas, sendo que $42 \%$ se encontra na faixa etária produtiva de 20 a 49 anos, o que implica uma força de trabalho presente na propriedade (Tabela 2).

Já o Tamarineiro II Sul possui 243 lotes e área total de 9.345,2180 ha. Nele estão localizadas as outras áreas coletivas de reserva legal: reserva 01 de 36,9679 ha, reserva 02 com 60,2532 ha, reserva 03 com 777,6452 ha e reserva 04 com 1.252,8642 ha. Possui um núcleo urbano de 24,1987 ha, onde não existem benfeitorias. Pelo assentamento passa o gasoduto, exigindo reserva de 22,9691 ha, que acaba sendo um passivo ambiental presente

5 Entrevista realizada no dia 17 de outubro de 2011. 
na área. Possui 736 moradores, sendo que 37,36\% da população se encontra na faixa etária produtiva, o que implica em disponibilidade de força de trabalho familiar (Tabela 3).

Tabela 2 - População do assentamento Tamarineiro II Norte, segundo classes de idade, Corumbá-MS, 2012

\begin{tabular}{|c|c|c|c|c|c|c|c|c|c|c|c|}
\hline \multirow[b]{2}{*}{ Sexo } & \multicolumn{11}{|c|}{ Faixa etária (anos) } \\
\hline & $<1$ & 1 a 4 & 5 a 6 & 7 a 9 & $\begin{array}{c}10 \mathrm{a} \\
14\end{array}$ & $\begin{array}{c}15 \mathrm{a} \\
19\end{array}$ & 20 a 39 & $\begin{array}{c}40 \mathrm{a} \\
49\end{array}$ & $\begin{array}{c}50 \mathrm{a} \\
59\end{array}$ & $>60$ & Total \\
\hline Masculino & 1 & 10 & 3 & 12 & 23 & 23 & 56 & 22 & 14 & 26 & 190 \\
\hline Feminino & 1 & 7 & 7 & 9 & 23 & 15 & 56 & 16 & 12 & 21 & 167 \\
\hline Número de Pessoas & & 17 & 10 & 21 & 46 & 38 & 112 & 38 & 26 & 47 & 357 \\
\hline
\end{tabular}

Fonte: SAS/DAB-DATASUS; SMS; SIAB, 2012.

Tabela 3 - População do assentamento Tamarineiro II Sul, segundo classes de idade, Corumbá-MS, 2012

\begin{tabular}{c|c|c|c|c|c|c|c|c|c|c|c}
\hline \multirow{2}{*}{ Sexo } & \multicolumn{10}{c}{ Faixa etária (anos) } \\
\cline { 2 - 33 } & $<1$ & 1 a 4 & 5 a 6 & 7 a 9 & $\begin{array}{c}10 \text { a } \\
14\end{array}$ & $\begin{array}{c}15 \text { a } \\
19\end{array}$ & 20 a 39 & $\begin{array}{c}40 \text { a } \\
49\end{array}$ & $\begin{array}{c}50 \text { a } \\
59\end{array}$ & $>60$ & Total \\
\hline Masculino & & 16 & 10 & 21 & 53 & 40 & 93 & 47 & 51 & 76 \\
\hline Feminino & & 13 & 11 & 23 & 37 & 35 & 83 & 52 & 39 & 36 & 736 \\
\hline Número de Pessoas & & 29 & 21 & 44 & 90 & 75 & 176 & 99 & 90 & 112 & \\
\hline
\end{tabular}

Fonte: SAS/DAB-DATASUS; SMS; SIAB, 2012.

O assentamento Paiolzinho possui 70 lotes e sua área total é de 1.197,5344 ha, dos quais 42,9234 ha são destinados ao núcleo comunitário onde está instalada a Escola Polo Rural Paiolzinho, que atende também aos assentamentos Tamarineiro II Norte e Sul, Taquaral e a comunidade rural Jacadigo. A escola possui uma quadra de esportes que é cedida nos fins de semana para os moradores praticarem esportes. Também existe outra quadra de esportes que pertence à comunidade, mas se encontra abandonada, onde é visível a presença de matagal. Há no local um resfriador de leite, mas que por falta de organização associativa e apoio governamental vem apresentando dificuldades de funcionamento. A população total do assentamento Paiolzinho é de 226 pessoas (Tabela 4) e, como nos outros assentamentos vizinhos, a maioria se encontra na faixa etária produtiva.

Tabela 4 - População do assentamento Paiolzinho, segundo classes de idade, Corumbá-MS, 2012

\begin{tabular}{|c|c|c|c|c|c|c|c|c|c|c|c|}
\hline \multirow[b]{2}{*}{ Sexo } & \multicolumn{11}{|c|}{ Faixa etária (anos) } \\
\hline & $<1$ & 1 a 4 & 5 a 6 & 7 a 9 & $\begin{array}{c}10 \mathrm{a} \\
14\end{array}$ & $\begin{array}{c}15 \mathrm{a} \\
19\end{array}$ & $\begin{array}{c}20 \mathrm{a} \\
39\end{array}$ & $\begin{array}{c}40 \mathrm{a} \\
49\end{array}$ & $\begin{array}{c}50 \mathrm{a} \\
59\end{array}$ & $>60$ & Total \\
\hline Masculino & & 9 & 4 & 6 & 15 & 8 & 38 & 18 & 13 & 18 & 129 \\
\hline Feminino & & 1 & 7 & 4 & 14 & 12 & 28 & 12 & 13 & 6 & 97 \\
\hline Número de Pessoas & & 10 & 11 & 10 & 29 & 20 & 66 & 30 & 26 & 24 & 226 \\
\hline
\end{tabular}

Fonte: SAS/DAB-DATASUS; SMS; SIAB, 2012.

Em relação ao abastecimento de água os assentamentos possuem poços que, através de rede encanada, distribuem água nos lotes. De acordo com o PDA Tamarineiro II e Paiolzinho (2002), esses assentamentos dispõem de sete poços artesianos, sendo 4 no Tamarineiro II Sul, 1 no Paiolzinho e 2 no Tamarineiro II Norte. Todos os lotes possuem 
energia elétrica monofásica, não suportando alguns equipamentos fundamentais para o trato agropecuário, como por exemplo: trituradores, bomba d'água, dentre outros. Contudo, a carência de água e a água salobra é um dos maiores problemas enfrentados pelos assentamentos.

A bovinocultura é a principal atividade agropecuária desenvolvida nos assentamentos, além da agricultura de subsistência com a venda de excedentes e a criação de pequenos animais. Porém, a atividade agrícola é desenvolvida juntamente com outras atividades não agrícolas, caracterizando o fenômeno da pluriatividade.

Atualmente os assentamentos não recebem assistência técnica de empresa privada ou governamental. As limitações do meio físico, como a falta de água, os afloramentos rochosos e também a ausência de métodos e técnicas adequadas de produção, seja por falta de conhecimento e/ou acompanhamento técnico, resulta em algumas criatividades. Assim, a maioria das famílias diversifica a atividade agrícola nos lotes, além de praticarem atividades como trabalhos braçais, roçadas para outros parceleiros e até mesmo em fazendas vizinhas. Existem, também, lotes cujos membros obtêm a renda fora da propriedade somente com atividades não agrícolas e não utilizam seu próprio lote para fins produtivos, caracterizando a presença de novas funções e usos desses territórios.

\section{EL CARMEN DE LA FRONTERA}

A comunidade boliviana El Carmen de la Frontera é fruto da incursão de um grupo de soldados que se estabeleceram no local há 108 anos. Os entrevistados locais apontam que o deslocamento deles ocorreu pela motivação do Estado em proteger seus limites durante a Guerra do Chaco. Essa afirmação é frequente em todos eles. Contudo, essa guerra data dos anos 1930 e, se diminuídos dos tempos atuais o tempo que eles afirmam estar no local, tem-se 1907 como a possível data de chegada deles na localidade. Portanto, a lógica de ocupação pode ter sido outra, ou seja, o inimigo a ser barrado de sua expansão não era paraguaio, mas brasileiro. Vale lembrar que a questão do Acre havia sido parcialmente resolvida pouco tempo antes (1903, pelo Tratado de Petrópolis). Isso confirmaria a discussão inicial de que a colocação de assentamentos humanos tem a ver com a defesa dos limites territoriais pelos estados nacionais.

Trata-se de uma comunidade campesina, que está localizada na zona rural do município de Puerto Quijarro, Bolívia. Está localizada ao lado do assentamento Tamarineiro I e à frente do Tamarineiro II Sul, conforme demonstrado na Figura 1. O nome El Carmen de la Frontera se refere à sua padroeira, a Nossa Senhora do Carmo, uma santa que foi doada à comunidade pelo líder religioso, "um rezador", que morava no local, o Sr. João da Cruz. As entrevistas apontaram que a ocupação foi tranquila, pois se tratava de "território de ninguém", do lado boliviano. Vale destacar que a maioria dos moradores possuem laços de parentesco entre si.

O acesso se dá pela estrada Jacadigo, localizada no Brasil, não existindo nenhum impedimento ou barreira física para entrar na comunidade. A sensação é de estar entrando 
em um dos assentamentos brasileiros localizados à beira da estrada. Porém, uma ou outra bandeira boliviana hasteada em taquaras, no alto ou em frente de algumas casas, sinaliza a localização em outro território. As cores amarela, vermelha e verde (referentes à bandeira boliviana) também colorem e se destacam na placa da guarita e cancela do posto militar, localizado ao fundo da paisagem do lugar. Existe ainda o histórico marco de concreto que está fincado na entrada da comunidade, às margens da estrada Jacadigo.

A atividade principal desenvolvida era a agricultura de subsistência e comercialização dos excedentes para sobreviverem. Desde essa época já existiam trocas comerciais entre os agricultores bolivianos e o comércio em Corumbá, principalmente com os mercadinhos que comercializavam hortifrutigranjeiros. Isso pode ser observado no depoimento de uma moradora local6: "Meu avô, Sr. João Poñe, ex-combatente, tinha uma moenda de cana, plantava mandioca, banana, batata e levava no carro de boi para vender na vendinha em Corumbá, às vezes recebiam em moeda, mas na maioria das vezes trocavam por mantimentos".

Quando o Grupo Chamma, empresa siderúrgica, se instalou na região, muitos dos moradores trabalharam temporariamente nas fazendas, para atender a demanda da siderúrgica, sendo essa a renda familiar por muitos anos, até a doação e desapropriação das terras pelo INCRA. Nessa época as famílias bolivianas moravam na fazenda para trabalharem e alguns membros das famílias nasceram no Brasil. A fala de um morador antigo é bastante representativa daquele contexto ${ }^{7}$ :

Aqui onde é Carmem chamava "picada" e do outro lado da rua onde é o assentamento chamava "Acurizal", eu morava lá com minha família. Eu nasci lá. Eu sou fronteiriço e falo que sou brasileiro. Trabalhamos pro Chamma e voltamos de vez aqui quando acabou o trabalho.

Atualmente essa comunidade campesina continua com a mesma distribuição espacial das propriedades que existia na época de sua fundação. As propriedades não apresentam área definida e estão basicamente distribuídas em volta de um núcleo comunitário, onde as casas são bem próximas uma das outras como uma aldeia e são em torno de 30 famílias. A prefeitura reconhece que "a comunidade ainda não é urbanizada" e, até por isso, as propriedades não são demarcadas. As moradias são na maioria de madeira, rústicas, com telhados de eternit ou palha de acuri (palmeira nativa da região) e piso sem revestimento, construídas pelos próprios moradores.

No núcleo comunitário se encontram as infraestruturas de uso coletivo: as igrejas nova e antiga, a escola de alvenaria com pequeno playground, um galpão denominado casa comunal onde são realizadas reuniões e festas comunitárias, um campinho de futebol e um posto militar que faz o controle de quem entra e sai da Bolívia, pois por ali é possível acessar as estradas que levam a Puerto Suárez e Puerto Quijarro. No fundo da comunidade existe um cemitério, onde são enterrados seus moradores. 
A comunidade não possui assistência técnica, posto de saúde e meios de comunicação coletivos. O barracão é utilizado como posto de saúde quando, de 15 em 15 dias, médicos e dentistas da Prefeitura de Puerto Quijarro oferecem assistência médica (clínica geral). Por isso, na maioria das vezes, os moradores procuram os atendimentos médicos no lado brasileiro, nos assentamentos e, principalmente, nos postos de saúde da cidade de Corumbá, onde o atendimento médico é mais específico e gratuito.

O abastecimento de água é por rede encanada. A bomba leva a água da caixa para as casas. Todas as moradias possuem energia elétrica que chegou na comunidade há apenas dois anos. O saneamento básico também é precário, não existindo fossa séptica, sendo os dejetos depositados a céu aberto. Muitos possuem televisão (só funciona canal brasileiro), celular (brasileiro e/ou boliviano) e, principalmente, rádio, no qual ouvem músicas tanto brasileira como boliviana.

Contudo, o local é marcado por forte simbolismo. Os símbolos da história e das hierarquias locais estão distribuídos por toda a comunidade rural boliviana. A cruz, que simboliza a presença da igreja católica e o seu domínio no local, está presente em vários pontos, inclusive na entrada da comunidade.

O catolicismo é a religião predominante desde o seu surgimento, inclusive a padroeira da comunidade é uma santa católica, Nossa Senhora do Carmo. A imagem da santa venerada (um quadro) pertencia a um dos moradores antigos e foi doada para a comunidade. Com o tempo, a igreja católica de Puerto Quijarro, cujos padres vão rezar missa semanalmente na comunidade, construiu uma escultura representativa da santa e doou para a localidade.

Quanto à produção agrícola, atualmente, são poucas as famílias que desenvolvem a agricultura para a comercialização. A maioria das famílias planta para o consumo próprio e as que trabalham na localidade se dedicam a atividades não agrícolas, como o magistério e a comercialização de bebidas e mantimentos.

Eventualmente os moradores da El Carmen de La Frontera compram produtos agrícolas dos assentados de Corumbá, principalmente hortícolas. Também compram produtos agrícolas na Bolívia, principalmente em Puerto Quijarro, para consumo próprio e até mesmo para comercialização nas feiras e mercados, funcionando como uma estratégia de agregação de renda.

Na comunidade El Carmen de la Frontera a dicotomia entre os tempos presente e passado é frequente no imaginário coletivo dos mais antigos. As pessoas expressam a dureza e a dificuldade dos dias atuais, como a falta de emprego e fazem comparações com a fartura de antigamente, propiciada pela disponibilidade de serviços oferecidos nas fazendas do Grupo Chamma. As palavras de um antigo morador do local ${ }^{8}$ ilustram essa memória:

Eu morei do outro lado, trabalhei lá no Chamma com madeira, tirava lenha de metro no machado e carregava da mata para o caminhão. Mas recebíamos em dinheiro brasileiro e comprávamos em mantimento. Naqueles tempos, custava cinquenta réis

8 Entrevista realizada no dia 30 de setembro de 2011. 
um quilo de carne seca e podia comprar quase meio saco de carne. Eu me lembro de tudo... Hoje em dia, dona, isso não volta mais.

A maioria das pessoas ainda trabalha no Brasil, na cidade ou em fazendas de Corumbá, executando trabalhos braçais e voltando esporadicamente para a comunidade, geralmente nos finais de semana. A possibilidade de ganhar em moeda brasileira (mais valorizada que o peso boliviano, moeda boliviana) atrai os moradores. A falta de trabalho é um dos maiores problemas enfrentados pelos assentamentos rurais brasileiros e pela comunidade El Carmem de la Frontera nessa área de fronteira.

\section{A DIMENSÃO SOCIOPOLÍTICA DA ÁREA ESTUDADA}

Uma vez descrito cada um dos territórios que compõem a fronteira estudada, cabe analisar como eles se estruturam politicamente a fim de tentar entender as dificuldades e possibilidades de desenvolvimento territorial dos mesmos. Para a proposição de alternativas desenvolvimentistas, fundadas no escopo teórico abordado anteriormente, faz-se necessário discutir a trajetória de participação dos grupos sociais. E essa condição é um forte complicador na área estudada.

No lado brasileiro da fronteira existem seis associações de produtores cadastradas, com CNPJ. São consideradas sociedades civis sem fins lucrativos, regidas por estatutos. São independentes e deveriam reunir seus associados mensalmente para as prestações de contas, mas isso não ocorre, pois efetivamente não existe pagamento pela maioria dos associados. Os presidentes se reúnem com os associados para resolverem os problemas comuns dos assentamentos apenas quando estimulados por agentes exógenos, como o Sindicato dos Trabalhadores Rurais, o INCRA, a AGRAER, universidades, dentre outros.

No lado boliviano, El Carmen de la Frontera, apesar de 108 anos de existência, não está organizada socialmente como instituição jurídica, tampouco ligada a nenhum movimento social. Porém, a comunidade tem um representante, o prefeito (título vinculado a Alcaldia de Puerto Quijarro, inclusive com salário), que é responsável por atender os interesses da comunidade, inclusive de tratar de assuntos externos - como a busca de melhorias na infraestrutura.

As associações dos agricultores dos assentamentos brasileiros não estão articuladas internamente, nem com as demais associações, e tampouco com os bolivianos, do ponto de vista de cooperação interinstitucional.

Para que ocorra o desenvolvimento, o território deve ser considerado para além da simples demarcação geográfica. Ou seja, um espaço onde são construídas relações econômicas, sociais, políticas, culturais entre as pessoas e os lugares, e que são frutos de construções histórico-culturais e da inserção de si próprio no mundo global, onde as materialidades são reflexos das imaterialidades e das ações dos agentes e atores do espaço.

O desenvolvimento territorial implica uma estratégia de empoderamento local que ocorre a partir da coadunação das relações de poder existentes num território em prol de sua comunidade e deve ser estimulado individual e coletivamente. Para Antunes (2002, 
p. 98) "é um processo que tem origem dentro das pessoas, no seio das comunidades e das organizações locais". Deve considerar as relações de poder existentes nas famílias, nas esferas de mercado, nas organizações e movimentos da sociedade civil.

Nesse sentido, a comunidade boliviana apresenta mais condições de se dinamizar internamente, porém, há dificuldades de articulação para além de seus limites. Nela, as famílias tradicionais desempenham forte liderança, a igreja católica é muito influente e o Estado presente apenas nos eventos e materializado na guarnição militar local.

Apesar de o prefeito ser o representante que simboliza a presença do Estado no lugar, a comunidade mantém uma estrutura organizacional informal, que foi estabelecida pelos pioneiros e que tentam preservar, apesar de incompleta, o que demonstra a ausência da gestão participativa dos moradores no lugar. Ela deveria ser composta de forma hierárquica por um representante da alcadia (prefeitura), presidente do Comitê de Base e Território, Comitê Cívico, presidente da Junta de Pais e Famílias, vice-presidente, secretário, tesoureiro e uma mesa diretiva (composta por pais de famílias e moradores da comunidade rural).

De acordo com o depoimento dos moradores, essa estrutura existe apenas nas atas das reuniões, mas nunca foi colocada na prática. Efetivamente, somente o prefeito e o presidente do Comitê de Base e Território existem nessa estrutura. A função desse último é zelar pelo bem da comunidade e tentar buscar soluções para as necessidades comunitárias, inclusive de infraestrutura, elaborar projetos e propostas e levar ao conhecimento do Comitê de Vigilância, da Prefeitura de Puerto Quijarro, para discussão de soluções dos problemas comunitários. Na visão da comunidade, não há efetividade pela falta de um trabalho coletivo de seus representantes. Eles trabalham individualmente, o que acaba enfraquecendo as forças locais e impedindo que as necessidades dos moradores sejam atendidas. Por causa disso, as pessoas mais jovens acabam indo embora do lugar, conforme a fala de uma moradora9:

A nossa Carmem não está funcionando muito bem. Falta uma pessoa com ideia e que saiba como fazer. Sinto que a minha comunidade está piorando cada dia mais, pois estão indo embora, por falta de trabalho. Terra tem, mas tem que vir gente de fora para trazer trabalho.

Nota-se que na comunidade a família, assim como a religião, é colocada em destaque e sempre reforçada a sua importância junto aos locais, simbolizando a força daqueles que de fato exercem o poder na comunidade. Mesmo na organização social, essas pessoas, direta ou indiretamente, ocupam os lugares de importância social em que conseguem, de alguma forma, controlar, coordenar e orientar o destino do lugar, garantindo e reforçando a manutenção dos seus valores que há décadas estruturam comunidade. Essa postura é reforçada com o entendimento de Gazeneuve e Victoroff (1982, p. 241) quando sugerem que "a comunidade é uma coletividade na qual os membros estão unidos por laços tanto mais forte quanto é certo não se tratar de laços explícitos e de contrato, mas se alimentam do passado comum, da tradição, do mito, do sangue, etc...".

9 Entrevista realizada no dia 26 de setembro de 2011. 
Os representantes não são escolhidos por voto, mas existe forte disputa de poder, onde o escolhido é aquele com maior influência na comunidade, devendo ser "aprovado" pelo Estado. Os cargos são ocupados por gente nascida preferencialmente no local, demonstrando o poder dos fundadores e a obstrução de ingresso de outros na estrutura social. Essa dificuldade pode ser percebida na fala de um brasileiro, morador de El Carmen de la Frontera há vinte e cinco anos ${ }^{10}$ :

Aqui é difícil melhorar, não mexo com organização ou essas coisas aqui. Pois eu queria mexer com um político da Bolívia, falei da minha proposta de trabalho, fui pedir um posto de saúde, que colocassem um mercado campesino para o pessoal vender as coisas deles aqui. Mas os mais antigos não aceitaram... Ficaram com ciúmes e disseram que não sou nascido aqui. Encerrei, para o pessoal não virar contra mim.

Nesse sentido, a força dos pioneiros é um fator limitante para a promoção de ideias inovadoras de desenvolvimento, constituindo-se num obstáculo forte a ser superado. A comunidade se reúne mensalmente, ou quando necessário, para tratar dos assuntos de interesse comum. Não é cobrada taxa de adesão ou participação aos moradores, não havendo, portanto, arrecadação comunitária por parte de seus representantes.

Existe um Comitê de Festejo, composto por aproximadamente 12 pessoas que têm a função de arrecadar fundos para a realização dos eventos e algumas melhorias em prol da comunidade como, por exemplo: melhoramentos ou benfeitorias na igreja e providências das bebidas para serem vendidas na festa de Nossa Senhora do Carmo. As pessoas que compõem esse Comitê são moradores locais e parentes que moram em Corumbá, mas que sempre estão presentes na comunidade.

Nos assentamentos rurais localizados no lado brasileiro da fronteira, os estatutos das associações são muito semelhantes e a escolha do presidente é feita através de eleições a cada dois anos, e nas quais apenas os associados têm direito a voto. Aos associados é cobrada uma taxa de contribuição mensal que varia de $\mathrm{R} \$ 1,00$ a $\mathrm{R} \$ 5,00$ reais, porém, segundo os presidentes das associações não há muita adesão, sendo que um dos maiores problemas enfrentados é a falta de cooperação, interesse em resolver os problemas da comunidade e assumir compromissos em prol do coletivo. As associações é que fazem a gestão da água e a manutenção dos poços. Na tomada de decisões e busca de benefícios os produtores não participam, deixando a competência para a diretoria, o que demonstra um papel passivo e também a falta de coesão social desses territórios.

O assentamento Tamarineiro I possui uma única entidade representativa, a Associação dos Pequenos Produtores Rurais do Assentamento Tamarineiro, fundada em 1987, ligada ao Sindicato dos Trabalhadores Rurais (STR) de Corumbá, que por sua vez é vinculado à Federação dos Trabalhadores em Agricultura (FETAGRI). A associação possui 2 tratores para uso da comunidade: 1 Massey Fergusson 275 e 1 Ford 6600, que são utilizados para o preparo do solo. Os sócios pagam R\$ 50,00/hora e os não-sócios $\mathrm{R} \$$ 60,00/hora. O próprio presidente da associação é o tratorista. Conta, ainda, com os seguintes equipamentos: 2 grades aradoras, 2 tanques pipa de 3.000 litros, 1 sulcador de linha, trilhadeira de cereais e carreta. 
Nos assentamentos Tamarineiro II e Paiolzinho existem cinco associações: Associação dos Pequenos Produtores Rurais do Assentamento Tamarineiro II, fundada em 29 de maio de 1996; a Associação Tamarineiro Norte, constituída em 11 de junho de 1997; Associação dos Pequenos Produtores Rurais Nossa Senhora Auxiliadora, AUPRAT, criada em 11 de janeiro de 1997; a Associação dos Trabalhadores Rurais do PA Tamarineiro II e Paiolzinho, fundada em 15 de setembro de 1997 e a Associação dos Pequenos Produtores Rurais do Projeto de Assentamento Paiolzinho, criada em 10 de junho de 1997.

Um dos maiores problemas enfrentados pelas associações é a gestão da água. Segundo seus presidentes muitos produtores não colaboram por falta de recurso, principalmente na época da seca, quando a renda é pouca e acaba gerando conflitos com os que pagam a conta. Existe também a questão da manutenção das bombas e equipamentos, e muitos esperam do governo a resolução dos problemas.

Das seis associações, cinco são ligadas ao Sindicato dos Trabalhadores Rurais e FETAGRI, e apenas uma, a Associação dos Trabalhadores Rurais do PA Tamarineiro II e Paiolzinho, está vinculada ao Movimento dos Trabalhadores Rurais Sem Terra (MST). Segundo a presidente do STR, a união não ocorre devido à existência de movimentos sociais diferentes, com objetivos diferentes, gerando divergências de opiniões e disputas internas pelo controle territorial. Porém, não é a presença dos movimentos que impede a coesão social, mas as formas como as forças externas atuam sobre essas organizações, impedindo a busca de objetivos comuns.

\section{INTERAÇÕES SOCIAIS FRONTEIRIÇAS}

Os assentamentos rurais Tamarineiro I, Tamarineiro II e Paiolzinho possuem algumas características comuns como: são cortados por várias estradas vicinais e pela estrada municipal Jacadigo, que se configura como principal acesso a todos os assentamentos e comunidades dessa área rural, inclusive com El Carmem de la Frontera.

Nas fronteiras nas quais a ligação entre as comunidades é feita por uma ou mais estradas (e não nas conurbações urbanas completas, como Ponta Porã, Brasil, e Pedro Juan Caballero, Paraguai, por exemplo), parte significativa de seus cotidianos são nelas compartilhados. De acordo com Souza (2009), o cotidiano da fronteira é influenciado pela mobilidade constante da população. Nesse espaço rural fronteiriço, tal movimento é facilitado pela estrada Jacadigo, diariamente utilizada pelos moradores de ambos os lados para acesso aos centros urbanos, conforme mencionado anteriormente.

Essa estrada já foi palco de lutas pela terra, do nascimento dessas comunidades e de sua sobrevivência. Nela ocorrem os maiores fluxos de pessoas, informações, mercadorias. Funciona como o canal das convivências diárias entre os moradores, conforme expressou uma moradora de El Carmen de la Frontera ${ }^{11}$ : "Tenho algumas amigas no assentamento. A gente conversa no ônibus que vai para Corumbá. Já combinamos de encontrar em casa, mas ainda não deu certo [...]".

11 Entrevista realizada em 9 de outubro de 2011. 
A importância da estrada vem de longa data, assumindo racionalidades de uso em função da disponibilidade de tecnologias e recursos em cada etapa da história. Em meados do século XX, a estrada Jacadigo já dividia os territórios e também facilitava a contratação dos moradores de El Carmen de la Frontera pelo Grupo Chamma, onde hoje estão os assentamentos. A fala de um entrevistado ${ }^{12}$ demonstra que existia trabalho e, consequentemente, mais dinheiro e fartura, ao se referir à contratação pelo Grupo:

Nós moramos 20 anos lá e tínhamos terra lá e aproveitava. O empreiteiro nordestino que trabalhava com 60 homens pra cortar lenha pro Chamma, pagava o salário por produção e dava a terra e botava a gente pra trabalhar. Plantávamos pra comer (milho, arroz) e o que sobrava vendia na cidade. Nós tínhamos direito de armazém, ali onde está a escola Paiolzinho, e domingo a gente vinha fazer compras.

A disponibilidade de trabalho no outro lado da estrada permitiu que houvesse novas territorializações dos moradores mais antigos de El Carmen de la Frontera, que passaram a morar na fazenda, no lado brasileiro, para trabalhar. Muitos bolivianos e brasileiros trabalharam juntos, mesclando elementos culturais, como por exemplo, a língua. Os bolivianos aprenderam o idioma português e também adquiriram maneiras diferentes de se vestir. Uma entrevistada ${ }^{13}$ informou que a vestimenta era diferente na época de seu avô que falava castelhano, além de um dialeto chiquitano:

Eu era pequena, mas ouvia as tias de meus pais e meu avô falar o dialeto chiquitano e o castelhano também, mesmo trabalhando na empresa brasileira com os brasileiros. Depois, os brasileiros começaram também a falar algumas palavras no dialeto e os bolivianos, o português. A vestimenta era uma farda longa, de manga $3 / 4$ com babados. Hoje a geração que estuda no Brasil já fala o português, além do castelhano e usam "pantalonas", mas não falam o dialeto. A cultura se perdeu.

Após o término dos trabalhos no Grupo Chamma, a maioria voltou a morar na comunidade, incorporando traços da cultura brasileira. Na verdade, a cultura não se perdeu, mas se modificou. Os moradores trouxeram em suas bagagens novas vestimentas, modos de falar, inclusive tiraram documentos brasileiros, que aos poucos transformou a comunidade boliviana numa comunidade brasileira "camuflada", pois muitos tiveram seus filhos e os registraram no Brasil.

Hoje a maioria dos moradores de El Carmen de La Frontera são filhos, netos ou bisnetos dos pioneiros bolivianos que fundaram a comunidade, mas também são brasileiros que continuam tendo seus filhos e os registrando no Brasil. Isso aparece claramente na fala de uma entrevistada ${ }^{14}$, filha de pioneiro boliviano e brasileira: "Aqui a maioria das mães quando vai ganhar nenê vai para a maternidade de Corumbá, aí quando cumpre os sete dias já vai para o cartório de Ladário ou Corumbá fazer certidão de registro".

Os assentamentos contam com transporte coletivo diário para a cidade de Corumbá, funcionando duas vezes ao dia, no período matutino e vespertino, porém, os ônibus

\footnotetext{
12 Entrevista realizada em 16 de outubro de 2011.

13 Entrevista realizada em 26 de setembro de 2011.

14 Entrevista realizada em 16 de outubro de 2011.
} 
não possuem manutenção adequada e sempre apresentam problemas técnicos. Dentre as demais alternativas de transporte estão: bicicletas, carroças, motos e, em menor escala, automóveis.

Em relação à comunicação, não existem equipamentos para uso coletivo, com exceção de um telefone público no assentamento Paiolzinho. Porém, a maioria dos parceleiros possuem celulares, rádio e TV.

Os assentamentos não possuem nenhuma festa tradicional, nem datas comemorativas. Algumas festas religiosas são comemoradas anualmente por alguns assentados, em lotes individuais como: a festa de São João, São Sebastião, Nossa Senhora Aparecida e Santa Clara.

Os moradores de El Carmen de La Frontera realizam anualmente a festa tradicional da padroeira, comemorada em 16 de julho, sendo divulgada em rádios brasileiras e bolivianas. Nesse dia, recebem visitantes dos assentamentos vizinhos e outras partes do município de Corumbá e Ladário e de várias regiões da Bolívia, e comemoram a data com missa em espanhol, rezada pelo padre de Puerto Quijarro no barracão de festas da comunidade. Também são contratados grupos musicais de brasileiros e de bolivianos que tocam músicas e estilos musicais de ambos os países e a festa dura 24 horas, terminando no dia seguinte.

A festa é realizada pelos moradores que doam a carne para o churrasco. Cada família assa a carne em casa, na presença de amigos e parentes que vêm para o evento e, após o término da missa, todos levam a carne para compartilhar com os convidados, após a procissão. Segundo informações dos entrevistados locais, cada um contribui com aquilo que pode.

A procissão acontece depois da missa e consiste no percurso em torno do campo de futebol (cancha) do espaço comunitário. O padre segue à frente, juntamente com a imagem (escultura) da santa, que é carregada num andor pelos fiéis (Figura 2). Durante o percurso rezam e entoam cantos de louvor.

Figura 2 - Procissão durante o aniversário de El Carmen de la Frontera, 2012.

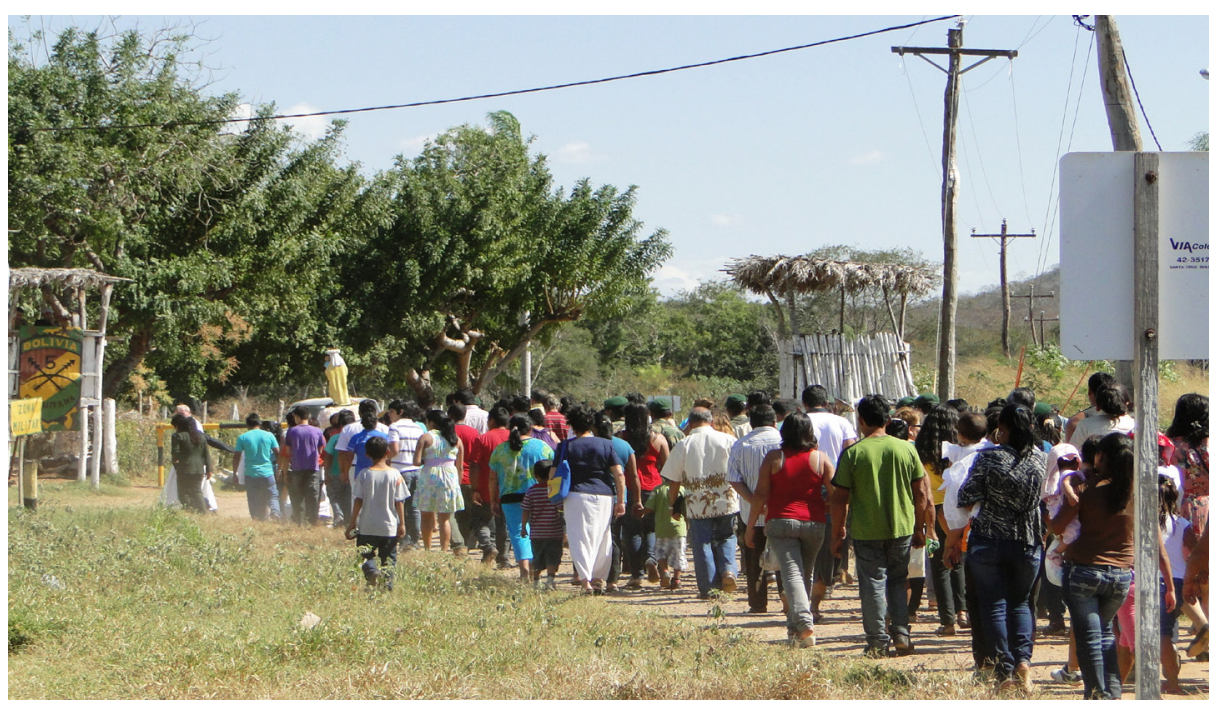

Autor: Sabatel, V.O., 2012. 
Segundo os moradores, a festa é um agradecimento à santa pelas graças recebidas e também uma maneira da comunidade sair do isolamento, inclusive de ser lembrada pelas autoridades bolivianas que participam do evento. A religião é uma forma de as famílias mais antigas reforçarem seu poder no local e de o Estado boliviano reforçar a sua presença nessa fronteira.

Nesse dia, as casas permanecem abertas e enfeitadas por bandeirolas multicores, tornando-se um ponto de encontro de parentes, amigos e outros visitantes. A festa é o momento de confraternização das famílias, podendo ser resumida da seguinte forma: começa com a missa, por volta das 9 horas, com batismos, crismas, casamentos, seguidos de procissão, churrasco comunitário (meio-dia) e baile durante a tarde e à noite inteira.

Os assentados da região prestigiam intensamente a festa, inclusive muitos levam os filhos para batizar ou crismar, além de casais participarem do casamento, principalmente quando uma pessoa do assentamento se casa com um membro da comunidade.

Por outro lado, os assentados reclamam por segurança pública. Não existe nenhuma unidade de patrulha nos assentamentos. Muitos assentados relacionam a falta de segurança à proximidade com a linha internacional de fronteira. Para muitos deles, se trata de uma área estratégica que permite a passagem de maquinários e equipamentos roubados e outras ilegalidades para o país vizinho, conforme depoimento de um morador do assentamento Tamarineiro II Sul ${ }^{15}$, que saiu há pouco tempo do lugar:

[...] a localização dos assentamentos próximos à fronteira é um caos. A fronteira é clandestina, é o mundo da informalidade, não é bom de viver nesse lugar. Ali há muitos roubos. Eles compram o que é roubado aqui. Mas não são só eles, os brasileiros também, pois são os atravessadores. A fronteira me assustava, eu tinha medo dessas pessoas, pela falta de segurança no lugar.

Segundo o depoimento de outro assentado do Tamarineiro II Sul ${ }^{16}$, morar na fronteira é estar em constante estado de alerta e medo:

Morar num lugar onde atravessou tá no Brasil; atravessou tá na Bolívia é ruim, pois facilita muita coisa errada como a entrada de drogas no assentamento que é um lugar de passagem e também alvo para consumo. Os jovens são os mais prejudicados. A gente não descansa bem, temos medo de invasão. Outro dia entraram no Paiolzinho dando tiro no lote, não sei quem foi, mas falaram que foi boliviano e brasileiro junto. Chamamos a polícia, mas ninguém apareceu. Eu tenho medo de denunciar, pois já recebi ameaças de morte por isso e também porque quando venho trabalhar a minha família fica por lá.

Nessa perspectiva, a fronteira é vista como um lugar de perigo, com entrada e saída de contraventores e de mercadorias ilícitas. Isso acarreta prejuízos para a imagem dos assentados. Seguidamente se observam barreiras do exército e da Polícia Federal na estrada Jacadigo. Nas palavras de um morador do PA Tamarineiro I"17: "Ali na fronteira

15 Entrevista realizada em 24 de novembro de 2011.

16 Entrevista realizada em 2 de dezembro de 2011.

17 Entrevista realizada em 28 de agosto de 2011. 
passa muitas coisas, por isso a polícia obriga a gente parar. Outro dia revistaram a minha filha, eles acham que a gente também está levando alguma coisa". Fica evidente a desconfiança nas pessoas que vivem no assentamento pela imagem que essa fronteira transmite aos olhos das instituições brasileiras de segurança pública.

Certamente essa imagem é reverberada para os citadinos, agravando os relacionamentos desses rurais com as pessoas e o comércio das cidades fronteiriças.

\section{À GUISA DE CONCLUSÃO: POSSIBILIDADES OU ENTRAVES AO DESENVOLVIMENTO TERRITORIAL FRONTEIRIÇO}

Nesse espaço rural fronteiriço, apesar da paisagem ser aparentemente homogênea, cada comunidade instalada possui características e temporalidades particulares. A partir da descrição e análise das mobilidades e territorialidades individuais, carregadas de informações coletivas, é possível compreender cada arranjo territorial. A fronteira é resultado da composição dessas totalidades, apresentando problemas comuns, como dificuldades no setor de saúde, carência de água (para consumo e para produção) e a falta de postos de trabalho para a maioria dos membros dessas comunidades.

Observou-se que, apesar da existência de associações de produtores, não é notada a participação efetiva de seus membros na mesma. Não se tem o conhecimento de que o poder político está no grupo e não no dirigente. Isso se torna um entrave ao desenvolvimento induzido pelas instituições governamentais, pois a única forma eficiente de ação em territórios fronteiriços é, pelo diálogo, aproveitar as possibilidades de complementariedade produtiva. Não se pode esquecer que o Estado executa ações apenas no âmbito do seu território.

Contudo, as relações sociais e de trocas existentes entre os moradores nessa fronteira são embriões para otimizar as oportunidades e estimular políticas públicas de desenvolvimento territorial. Cabe, portanto, um grande esforço por parte dos representantes das instituições governamentais brasileiras (e bolivianas, no outro lado da fronteira) em fomentar a participação nas associações existentes, capacitar para o desenvolvimento, incentivar o diálogo com os vizinhos bolivianos e construir um projeto coletivo de desenvolvimento rural fronteiriço. Precisa-se conduzir e chegar a um processo de governança territorial.

As comunidades fronteiriças precisam adotar medidas comuns ou complementares, pois do contrário serão concorrentes. Na verdade carecem de cooperação e não de competição para permanência no meio rural. O conhecimento dos problemas comuns e a participação dos moradores da fronteira nas discussões para busca de soluções junto ao Estado é fundamental para a construção de uma melhor condição de vida para esses camponeses.

\section{REFERÊNCIAS}

ANTUNES, Marta. O caminho do empoderamento: articulando as noções de desenvolvimento, pobreza e empoderamento. In: ROMANO, O.J.; ANTUNES, M. (Orgs.). Empoderamento e direitos no combate à pobreza. Rio de Janeiro: Action Aid Brasil, 2002. 
BENEDETTI, Alejandro. Lugares de frontera y movilidades comerciales en el sur sudamericano: una aproximación multiescalar. In. COSTA, E.A.C.; COSTA, G.V.L.; OLIVEIRA, M.A.M. (Orgs.). Fronteiras em foco. Campo Grande: Ed. UFMS, 2011. p. 33-55.

BRITTS, Joicy Karoline; COSTA, Edgar Aparecido da. Diálogo e desenvolvimento territorial. In: COSTA, Edgar Aparecido da Costa; SILVA, G.A.M; OLIVEIRA, Marco Aurélio Machado. (Org.). Despertar para a Fronteira. Campo Grande: Ed. UFMS, 2009. p. 161-180.

CARDOSO, E.L. et al. Solos do Assentamento Tamarineiro I - Corumbá, MS: caracterização, limitações e aptidão agrícola. Corumbá: Embrapa Pantanal, 2002. 26p. il. (Embrapa Pantanal. Documentos, 28).

COSTA, Edgar Aparecido da. Mobilidade e fronteira: as territorialidades dos jovens de Corumbá, Brasil. Revista Transporte y Territorio, v.2, no 9, 2013. p. 65-86.

COSTA, Edgar Aparecido da. Mexe com o quê? Vai pra onde? Constrangimentos de ser fronteiriço. In. COSTA, E.A.; COSTA, G.V.L.; OLIVEIRA, M.M.M. (Orgs.). Fronteiras em foco. Campo Grande: Ed. UFMS, 2011. p.131-170.

COSTA, Edgar Aparecido da. Ordenamento territorial em áreas de fronteira. In. COSTA, E.A.; OLIVEIRA, M.M.M. (Orgs.). Seminário de estudos fronteiriços. Campo Grande: Ed. UFMS, 2009. p. 61-78.

GAZENEUVE, Jean e VICTOROFF, David. Dicionário de Sociologia. Lisboa: Verbo, 1982.

GIRARDI, Eduardo Paulon. Atlas da questão agrária brasileira e cartografia geográfica crítica. Revista Confins, n. 5, 2009. p.1-9.

GUANZIROLLI, Carlos Enrique. Experiências de desenvolvimento territorial rural no Brasil. Niterói, RJ: Universidade Federal Fluminense, 2006.

HOUSE, J.W. The frontier zone: A conceptual problem for policy makers. International Political Science Review, v.1, n 4, 1980. p. 456-477.

MICHELOTTI, Fernando et al. O agrário em questão: uma leitura sobre a criação dos assentamentos rurais no sudeste do Pará. Anais... II Encontro da Rede de Estudos Rurais, Rio de Janeiro, 2007. 1 CD rom.

NOGUEIRA. Ricardo José Batista. Fronteira: espaço de referência identitária. Ateliê geográfico. Goiânia. v.1, n 2, 2007. p. 27-47.

OLIVEIRA, Tito Carlos Machado de. Tipologia das Relações Fronteiriças: elementos para o debate teóricopráticos. In: OLIVEIRA, T.C.M. (Org.). Território Sem Limites. Campo Grande: Editora da UFMS, 2005. p. 377-408

SABATEL, Vania de Oliveira; ZARATE, Suelen Soares; COSTA, Edgar Aparecido da. Territorialidades fronteiriças: o caso dos assentamentos rurais de Corumbá- MS na fronteira com a Bolívia. Revista Geopantanal, v. 7, $\mathrm{n}^{\mathrm{o}}$ 11, 2011.

SAQUET, Marcos Aurélio. Abordagens e concepções de território. São Paulo: Expressão Popular, 2007.

SOARES, Teixeira. História da formação das fronteiras do Brasil. Rio de Janeiro: Conselho Federal de Cultura, 1972.

SOUZA, Edson Belo Clemente de. O território e a região: análise de políticas públicas. In: SAQUET, Marcos Aurélio; SPÓSITO, Eliseu Savério (Orgs.). Território e territorialidades: teorias, processos e conflitos. São Paulo: Expressão Popular, Unesp, 2009. p. 341-365.

SOUZA, Marcelo José Lopes de. O território: sobre espaço e poder, autonomia e desenvolvimento. In CASTRO, I.E.; GOMES, P.C.C.; CORREAA, R.L. (Orgs.). Geografia: conceitos e temas. Rio de Janeiro: Bertrand Brasil, 1995. p. 77-116.

Recebido em 04-12-2012

Aceito para publicação em 06-09-2013 